\title{
Low Reverse Saturation Current Density of Amorphous Silicon Solar Cell Due to Reduced Thickness of Active Layer
}

\author{
S M Iftiquar* and Junsin $\mathbf{Y i}^{\dagger}$
}

\begin{abstract}
One of the most important characteristic curves of a solar cell is its current density-voltage (J-V) curve under AM1.5G insolation. Solar cell can be considered as a semiconductor diode, so a diode equivalent model was used to estimate its parameters from the $\mathrm{J}-\mathrm{V}$ curve by numerical simulation. Active layer plays an important role in operation of a solar cell. We investigated the effect thicknesses and defect densities $\left(\mathrm{N}_{\mathrm{d}}\right)$ of the active layer on the $\mathrm{J}-\mathrm{V}$ curve. When the active layer thickness was varied (for $\mathrm{N}_{\mathrm{d}}=8 \times 10^{17} \mathrm{~cm}^{-3}$ ) from $800 \mathrm{~nm}$ to $100 \mathrm{~nm}$, the reverse saturation current density $\left(\mathrm{J}_{\mathrm{o}}\right.$ ) changed from $3.56 \times 10^{-5} \mathrm{~A} / \mathrm{cm}^{2}$ to $9.62 \times 10^{-11} \mathrm{~A} / \mathrm{cm}^{2}$ and its ideality factor (n) changed from 5.28 to 2.02 . For a reduced defect density $\left(\mathrm{N}_{\mathrm{d}}=4 \times 10^{15} \mathrm{~cm}^{-3}\right)$, the $\mathrm{n}$ remained within $1.45 \leq \mathrm{n} \leq 1.92$ for the same thickness range. A small increase in shunt resistance and almost no change in series resistance were observed in these cells. The low reverse saturation current density $\left(\mathrm{J}_{\mathrm{o}}=9.62 \times 10^{-11}\right.$ $\left.\mathrm{A} / \mathrm{cm}^{2}\right)$ and diode ideality factor $(\mathrm{n}=2.02$ or 1.45$)$ were observed for amorphous silicon based solar cell with $100 \mathrm{~nm}$ thick active layer.
\end{abstract}

Keywords: Amorphous silicon solar cell, Diode equivalent model, Active layer thickness

\section{Introduction}

Photovoltaic solar cell is a very useful device to generate electricity from sunlight. Global warming, environmental pollution, cost of fossil fuel etc has created an atmosphere in which it becomes clear that better utilization of solar radiation for global energy demand is a right approach. Large scale photovoltaic research is going on for more than 30 years now and there has been significant progress for commercialization, yet the actual feature of solar cells are yet to meet all the critical aspects for large scale commercialization. The reasons can be many in number and type because various solar cells have been proposed and developed with various materials, structures, device characteristics, cost of production etc. However, the most important aspect for all these solar cells is its photo-voltaic conversion efficiency, estimated from standard current density - voltage (J-V) characteristic curve. The J-V characteristic curve is also a common feature that all the solar cells exhibit. Therefore it seems possible to identify few intrinsic characteristics of solar cell on which the J-V characteristic curve strongly depends on.

Single diode equivalent circuit of solar cell $[1,2]$ is one of the simplest models used to analyze it, although two diode model was also discussed [3, 4] in the context of understanding degradation. However, it is obvious that complication in the analysis increases with increased

$\dagger$ Corresponding Author: College of Information and Communication Engineering, Sungkyunkwan University, Korea. (yi@skku.ac.kr)

* College of Information and Communi-cations Engineering,

Sungkyunkwan University, Korea. (smiftiquar@gmail.com)

Received: October 15, 2015; Accepted: January 2, 2016 number of unknown parameters. So we adopted a simple single diode model to extract diode parameters of solar cell from its illuminated current density-voltage (J-V) characteristic curve.

There have been some popular techniques of evaluating the dynamic series and shunt resistances from the negative slope of the J-V curve near open circuit and short-circuit conditions respectively. However, this method may not result in a good estimation of these resistances [3], but can give a good starting point of our simulation. There is a possibility that the slope of the $\mathrm{J}-\mathrm{V}$ curve near the short circuit condition depends upon recombination loss of the photo generated carriers [5]. It was also observed that an increase in the open circuit voltage $\left(\mathrm{V}_{\mathrm{oc}}\right)$ is possible by a reduction in saturation current density [6]. In a dye sensitized solar cell, a variation in series resistance may lead to change in short circuit current density [7]. These observations further highlight that the mechanism of operation of a solar cell and its equivalent model parameters can be correlated. In 1994, an inverse modeling method was reported, by which the parameters were extracted [8]. It was also noted that there may be significant challenges in determining series resistance at the maximum power point [9].

Therefore, extraction of the solar cell circuit parameters is one of the most interesting aspects to understand the device. Various techniques have been adopted so far, like analytical method $[10,11]$ where various equations have been developed to use the J-V characteristic curves and solve for the parameters. Experimental technique was also proposed in which variation in illumination intensity and temperature was used to investigate solar cells meant for 
concentrated light [12], from which the parameters were extracted. Although several methods were suggested to extract these parameters, yet a systematic correlation between the diode parameters and intrinsic characteristics of cell of layers is not well known. We used a simple numerical simulation technique, and determined the diode parameters by Newton-Raphson method.

\section{Theoretical}

Diode equivalent parameters of solar cell can be described as a simple equivalent lump parameters of a cell that depends on the factors that affect operation of a solar cell. For example, increased defects in an active layer will degrade the cell performance. Measuring such a change in performance characteristics, like $\mathrm{J}-\mathrm{V}$ curve and extracting the diode equivalent circuit parameter may help to understand the solar cell better. This approach being a generalized one, and obtained from J-V curves, it can be applied to solar cells fabricated with any material or structure.

A conventionally known single diode model of solar cell is shown in Fig. 1 [1]. The Eq. (1) [1] can be called a modified Shockley diode equation, it gives the expression for the solar cell current density.

$$
J=J_{s c 0}-J_{0}\left[e^{\left(\frac{q V+q J R_{s}}{n k T}\right)}-1\right]-\frac{V+J R_{s}}{R_{p}}
$$

Here $R_{s}$ is series resistance, $R_{p}$ shunt resistance, $J_{s c 0}$ is strength of current source, $J_{0}$ is reverse saturation current density, $n$ is diode ideality factor or quality factor, $q$ is electronic charge. The $J_{o}\left[e^{(q V+q J R s) / n k T}-1\right]$ is coming from Shockley diode equation, $n k T / q$ can be called thermal voltage, which is $\sim 25.9 \mathrm{mV}$ at $300 \mathrm{~K}$ temperature. Numerical simulation was used to fit the Eq. (1) to the J-V characteristic curve, that we call diode simulation.

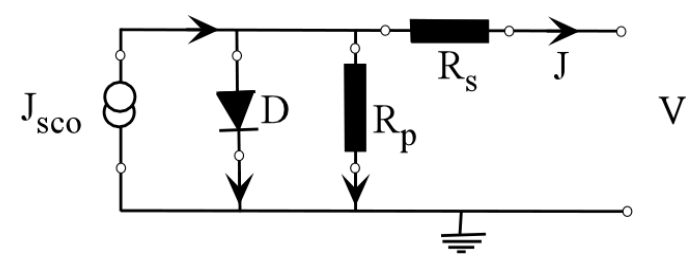

Fig.1. The single diode equivalent circuit of a solar cell

\section{Results and Discussion}

In order to have a better understanding on these parameters, we use AFORS HET simulation results of the J-V curves, as reported in [13]. Fig. 2 shows the diode simulation results (as continuous lines) in comparison to the

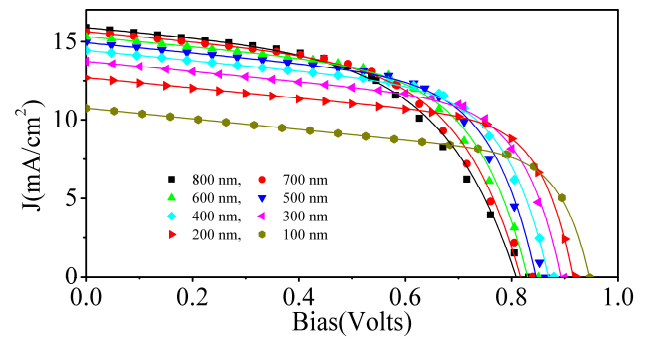

Fig. 2. J-V characteristics of solar cells having various ilayer thickness, as indicated in the legend. The data points are taken from [13], while the continuous lines are diode simulation with Eq. (1).

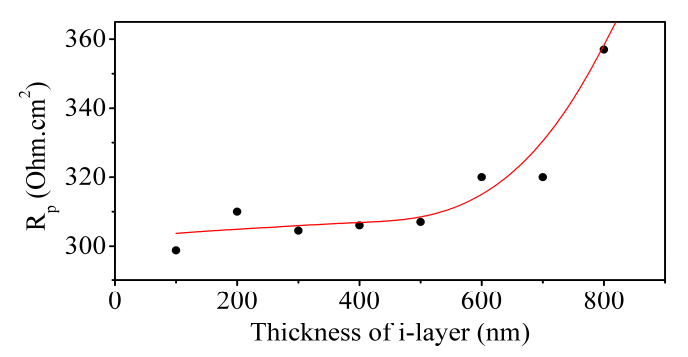

Fig. 3. Variation of shunt resistance $R_{p}$, of the solar cells having various i-layer thickness. The data points are the results from diode simulation, while the continuous lines are best fit lines, drawn to indicate average trend.

$\mathrm{J}-\mathrm{V}$ data points obtained from AFORS HET simulation. The details of the simulation parameters and cell characteristics can be found in [13]. A good match of the diode simulated $\mathrm{J}-\mathrm{V}$ curves can be observed for all the cells, especially for the cell with active layer thickness $(d)$ of $100 \mathrm{~nm}$.

The summary of the extracted parameters of the cells of Fig. 2, are given in Fig. 3,4,5, where the $R_{s}$ remains within 0.001 to $0.0022 \Omega . \mathrm{cm}^{2}$ while the variation of $R_{p}$ is shown in the Fig. 3. The shunt resistance increases with increased thickness of active layer.

\subsection{Shunt resistance, $R_{p}$}

A higher $R_{p}$ for a cell is better, because a lower number of photo generated charge carriers will be lost in an equivalent parasitic shunt circuit. However, here the $R_{p}$ remains lower than $1 \mathrm{k} \Omega . \mathrm{cm}^{2}$ and a marginal increase was observed with increased i-layer thickness. A lower value of $R_{p}$ may indicate that poorer electrical isolation between the p-type and n-type layers. When a physical separation between the p-type and n-type layers was increased by using thicker i-layer, the $R_{p}$ increased, indicating lower such loss of charge carriers.

\subsection{Diode ideality factor, $n$}

For an ideal diode the $n=1$, but in reality $n>1$ for most of the diodes. Looking into the modified Shockley diode Eq. 


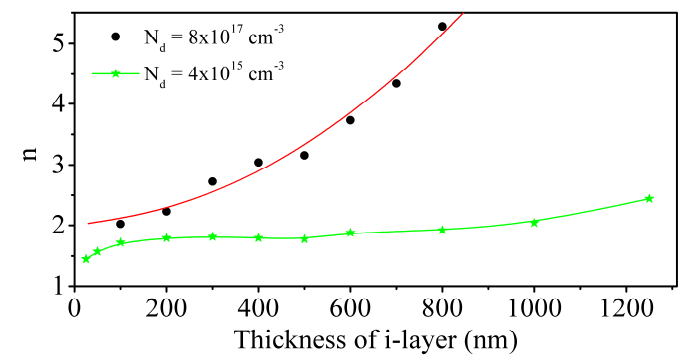

Fig. 4. Variation of diode ideality factor $n$ of the solar cells having various i-layer thickness, with active layer defect density, $N_{d}=8 \times 10^{17} \mathrm{~cm}^{-3}$ and $4 \times 10^{15} \mathrm{~cm}^{-3}$.

(1), the $n$ can also be interpreted as a factor by which the applied electrical bias $V$ is modified within the cell. Therefore, any imperfection or non-ideality in diode structure that influences field distribution within the active layer, leads to a reduction in effective $V$ in the form of higher ideality factor. Material defects can be one such imperfection. Because the amorphous silicon alloy has significantly large defect density, so generally $n>1$ is expected in such solar cells. When the active layer is thicker its total defects increases and hence the $n$ is expected to increase further, as can be seen in Fig. 4.

The diode ideality factor, as shown in the top of Fig. 4, with black circles, was unusually higher than 2 . So we performed a further analysis to understand a possible reason behind such a high $n$ [14]. Defects may have a role in this case as defect density $\left(N_{d}\right)$ for this trace was $8 \times 10^{17}$ $\mathrm{cm}^{-3}$, while that for the bottom curve with star symbol was $N_{d}=4 \times 10^{15} \mathrm{~cm}^{-3}$. Here, the two sets of $\mathrm{n}$ shows that the $n$ for cells with improved active layer (lower $N_{d}$ ) remains lower than that for the cells with more defective active layer, a trend that mostly in agreement with explanations given above for $n>1$. Therefore, it appears that the diode ideality factor strongly depends upon thickness and defect density of the active layer. The non-linearity of the traces indicates that the electric bias field inside the cell varies non-linearly with thickness of active layer.

\subsection{Reverse saturation current density, $J_{o}$}

The reverse saturation current density $\left(J_{0}\right)$ here can be considered to be related to loss of photo generated charge carriers at the defects due to recombination; as demonstrated by dark current measurements [15]. The recombination can grossly be classified as surface and bulk recombination. Bulk recombination depends on product of defect density and thickness, under constant surface area of the active layer. Thus, with higher defect density and/or thicker active layer the bulk recombination will dominate over the surface recombination [15]. In our investigation, the observed increase in the $J_{0}$ is primarily due to increased bulk recombination. In other words, when active layer thickness increases, total number of defects in the active layer increases, leading a larger bulk recombination of

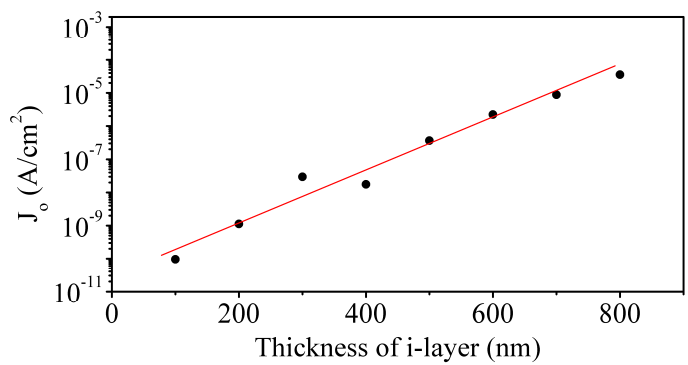

Fig. 5. Variation of reverse saturation current density, $J_{o}$, of the solar cells having various i-layer thickness.

photo generated charge carriers or $J_{0}$. Fig. 5 shows an exponential rise in $J_{0}$ with the increased i-layer thickness. Looking into Fig. 4, 5, it becomes clear that the $n$ and $J_{0}$ increases with thickness of active layer, a trend similar to that reported in Table I of [15].

It indicates that a thinner cell will have less recombination loss of charge carriers and lower diode ideality factor, both of which are favorable characteristics of a solar cell. However, thinner cell will have lower light absorption and hence lower current density. This limitation can be overcome to a great extent by adopting to light trapping schemes $[16$, 17].

Solar cell with thinner active layer is useful for cost reduction and lowering its light induced degradation. Our investigation indicates that thinner cells have better device parameters.

\section{Conclusion}

It is to be noted that the dynamic series and shunt resistances, as can be estimated from the slope on the J-V curves, are different from the static resistances of the diode model of the cell. Reverse saturation current density, diode ideality factor, shunt resistance can be the three important parameters of a solar cell. Increased $J_{o}$ and $\mathrm{n}$ indicates that cell is poorer than expected, while an increased $R_{p}$ is favorable. A systematic investigation of these parameters with variation of structural or design parameters of a solar cell or opto-electronic characteristics of the materials used in fabricating the solar cell, can give valuable information on how certain basic material or cell parameter affects performance of a solar cell. In order to obtain information on the $R_{p}, n, J_{o}$ parameters, a numerical simulation is useful. The diode simulation is a general approach, and independent of materials used for the device fabrication or design of the device, so the technique can be applicable to analyze any solar cell.

\section{Acknowledgements}

This work was supported by the Human Resources Development program (No.20144030200580) of the Korea 
Institute of Energy Technology Evaluation and Planning (KETEP) grant funded by the Korea government Ministry of Trade, Industry and Energy. This research was supported by Basic Science Research Program through the National Research Foundation of Korea(NRF) funded by the Ministry of Education. (NRF-2013 R1A1A2064769).

\section{References}

[1] J. C. H. Phang, D. S. H. Chan, J. R. Phillips, Accurate analytical method for the extraction of solar cell model parameters, Electron Lett, 20 (1984) 406-408.

[2] D. S. H. Chan, J. R. Phillips, J. C. H. Phang, A comparative study of extraction methods for solar cell model parameters, Solid-State Electron., 29 (1986) 329-337.

[3] S. Voswinckel, V. Wesselak, B. Lustermann, Behaviour of amorphous silicon solar modules: A parameter study, Sol. Energy, 92 (2013) 206-213.

[4] K. I. Kurobe, H. Matsunami, New two-diode model for detailed analysis of multicrystalline silicon solar cells, Jpn J Appl Phys Part 1 Regul Pap Short Note Rev Pap, 44 (2005) 8314-8321.

[5] C. Voz, J. Puigdollers, J.M. Asensi, S. Galindo, S. Cheylan, R. Pacios, P. Ortega, R. Alcubilla, Analysis of the dynamic short-circuit resistance in organic bulk-heterojunction solar cells: Relation to the charge carrier collection efficiency, Org. Electron.: phys. mater. appl., 14 (2013) 1643-1648.

[6] S. Yamamoto, A. Orimo, H. Ohkita, H. Benten, S. Ito, Molecular understanding of the open-circuit voltage of polymer:Fullerene solar cells, Adv. Energy Mater., 2 (2012) 229-237.

[7] R. Y. Yang, H. Y. Chen, F. D. Lai, Performance degradation of dye-sensitized solar cells induced by electrolytes, Adv. Mater. Sci. Eng., 2012 (2012).

[8] M. Zeman, J. A. Willemen, S. Solntsev, J. W. Metselaar, Extraction of amorphous silicon solar cell parameters by inverse modelling, Sol Energ Mater Sol Cells, 34 (1994) 557-563.

[9] J. Chen, Z. R. Du, F. Ma, F. Lin, D. Sarangi, B. Hoex, A. G. Aberle, Accurate extraction of the series resistance of aluminum local back surface field silicon wafer solar cells, Sol Energ Mater Sol Cells, 133 (2015) 113-118.

[10] J. Appelbaum, A. Peled, Parameters extraction of solar cells - A comparative examination of three methods, Sol Energ Mater Sol Cells, 122 (2014) 164-173.

[11] Z. Arefinia, A. Asgari, Optical and electrical modeling of solar cells based on graphene/Si nanowires with radial $\mathrm{p}-\mathrm{i}-\mathrm{n}$ junctions, Sol Energ Mater Sol Cells, 137 (2015) 146-153.
[12] E. Cuce, P. M. Cuce, T. Bali, An experimental analysis of illumination intensity and temperature dependency of photovoltaic cell parameters, Appl. Energy, 111 (2013) 374-382.

[13] S. M. Iftiquar, J. Jung, H. Park, J. Cho, C. Shin, J. Park, J. Jung, S. Bong, S. Kim, J. Yi, Effect of light trapping in an amorphous silicon solar cell, Thin Solid Films, 587 (2015) 117-125.

[14] S. M. Iftiquar, J. Yi, Determining criteria for nearideal operation of amorphous silicon solar cell, Conference PVSEC-25 (Nov. 15-20, 2015, Busan Korea), Abstact number: SiF-O-15.

[15] H. Sakai, T. Yoshida, S. Fujikake, T. Hama, Y. Ichikawa, Effect of $\mathrm{p} / \mathrm{i}$ interface layer on dark $\mathrm{J}-\mathrm{V}$ characteristics and Voc in p-i-n solar cells, J. Appl. Phys. 67 (1990) $3494-3499$.

[16] S. M. Iftiquar, J. Jung, C. Shin, H. Park, J. Park, J. Jung, J. Yi, Light management for enhanced efficiency of textured n-i-p type amorphous silicon solar cell, Sol Energ Mater Sol Cells, 132 (2014) 348-355.

[17] S. M. Iftiquar, J. Jang, H. Park, C. Shin, J. Park, J. Jung, S. Kim, J. Yi, Analysis of optical absorption and quantum efficiency due to light trapping in a n-ip type amorphous silicon solar cell with textured back reflector, Phys. Status Solidi A Appl. Mater. Sci., 211 (2014) 924-931.

S M Iftiquar He received Ph.D. from Jadavpur University on semiconductor and devices. His research interests include material science of crystalline, non-crystalline silicon alloys, perovskites, quantum dots as well as its device applications such as thin film photovoltaics, transistors and memory devices.

Junsin Yi He received Ph.D. in Electrical and Computer Engineering from New York State University at Buffalo on Semiconductor Devices. His research areas include thinfilm silicon-based devices. Applications of research include thin film transistors (TFTs) for displays, organic light emitting diodes, non-volatile memory, nano floating gate memory devices, and crystalline silicon solar cells. 